\title{
SIMULATION ANALYSIS OF ORDER PICKING EFFICIENCY WITH CONGESTION SITUATIONS
}

\author{
Klodawski, M. ; Jachimowski, R. ; Jacyna-Golda, I. ${ }^{* *} \&$ Izdebski, M. \\ *Faculty of Transport, Warsaw University of Technology, Warsaw, Poland \\ ${ }^{* * *}$ Faculty of Production Engineering, Warsaw University of Technology, Warsaw, Poland \\ E-mail: mkloda@wt.pw.edu.pl
}

\begin{abstract}
Paper presents analysis of the order picking system efficiency under congestion situations. Analysed picking system is manual and organized as picker-to-part system with very narrow aisles. About 150 different variants of the system was taken into consideration. Each of them is characterized by different storage policies (random, class-based and volume-based), number of order pickers and picking strategies (single picking and batch picking). Main attention was paid to picker blocking phenomenon and its impact on order picking efficiency. Authors explain where, when and why such situations may happen. Additionally, they point out how the number of pickers, storage policy and picking strategy impact pickers blocking and picking process efficiency. Due to complexity of presented issue, dynamics and volatility of picking processes, simulation method was implemented. (Received in January 2018, accepted in June 2018. This paper was with the authors 2 months for 1 revision.)
\end{abstract}

Key Words: Warehousing, Order Picking, Congestion, Simulation, Performance Analysis

\section{INTRODUCTION}

Logistics facilities like distribution warehouses influence the supply chain ability to satisfy customers' needs. The key task of warehouses is fulfilling customers' orders in the specified time and at the minimal cost. Therefore, there is a need to search for organizational and technological solutions to improve warehouse processes like order picking, ensuring smooth, quick and accurate fulfilment of orders [1-3].

Order picking is a key determinant of logistics service reliability [4]. Order picking processes can absorb up to $60 \%$ of FTE for all warehouse activities [5] and generate about $55 \%$ of costs [6]. Therefore, there is a need to minimize a time of orders fulfilment as well as to maximize a productivity and efficiency of picking processes.

There are three main types of order picking systems divided by a number of employees and type of picking process. Thus, there are manual, semi-automated, and automated order picking systems. In the manual (picker-to-product) system, pickers move to locations and pick manually items. A semi-automated (product-to-picker) system moves products from storage locations to picking station by internal transport means like carousels, vertical lift modules, SBS/RS [3], movable shelves [7], etc. Automated order picking systems are able to fulfil orders without any human assistance (e.g., A-frame).

Order picking process is very laborious. Manual order picking usually needs a number of pickers working simultaneously. It should potentially increase throughput of the system, but very often congestion issues occur. Congestion in manual order picking system is related to the situation when tasks of the order picker are interrupted by another picker while all requirements for a regular picking process are met. The picking process is considered as regular when the stream of orders is uninterrupted, all supporting systems (e.g. IT or equipment) are fit to work and interfaces with other areas (e.g. receiving, sorting, packaging or shipping areas) are in operation [8].

Congestion in order picking system was considered quite rarely in the literature. Ottjes and Hoogenes [9] focused on order picking trucks traffic in distribution centre. Their results 
showed that waiting time of order picking trucks (due to congestion) grows exponentially with the number of trucks.

In [10] the authors evaluated the influence of batch construction heuristics, three storage assignment policies (random, turnover-based and family-based) and traversal routing policy on order picking system throughput. In their research they also considered congestion issues. Results were derived from the simulation of a single hypothetical warehouse model.

Other publication [11] presents comparison of random and class-based storage policies with three routing policies (traversal, return and optimal). Congestion was analysed as total aisle blocking (if a picker reserved and entered the aisle, all other pickers must wait until this picker completed work and left that aisle to get in).

In researches [12] and [13] authors considered congestion in order picking area and influence of pick density on that congestion. Congestion was estimated as the percentage share of time in which pickers are blocked in relation to the entire picking process. In the first publication [12] the authors analysed order picking area with narrow aisles and in the second one [13] with the wide aisles. In both cases Markov chains were used in the tests.

Congestion aspects in order picking were also considered in [14]. Authors focused on the problem of selecting between a batch picking and a zone picking strategy. In their research the picking strategy selection decision was depended on pick-rate, picker blocking, workloadimbalance, and the sorting system requirements. To solve that issue, they proposed the cost model which was used to estimate the cost of both types of picking strategy.

Analysis of congestion in complex processes like order picking, require specific research methods. Simulation $[1,10,11,14]$ and queueing theory $[8,15]$ are the methods which are used most often.

In our research we would like to emphasize, that determining order picking process productivity depends on a wide variety of factors, including: area layout (see e.g.: [16, 17]), storage system configuration, storage assignment method, routing policy (see e.g.: [16, 18-20]), picking method, order picking strategy, number of pickers, material handling equipment, as well as congestion issues. All these factors should be taken into account during the research since omitting any of them can degrade analysis and make results only theoretical without practical application [1].

In this paper, we present an approach to estimate order picking efficiency with regard to factors listed above. We mainly focus on the impact of storage assignment method, number of pickers and picking strategy on congestion.

\section{PICKING STRATEGY AND PICKERS BLOCKING}

A picking strategy defines the manner in which pickers navigate within aisles of a picking area to pick up required items. The basic order picking strategies are:

- single picking (also discrete picking),

- batch picking,

- zone picking,

- and combinations of the above (e.g. zone-batch picking).

Single picking is a strategy in which a picker picks all items from a single order during a single pick-tour. This policy is preferred because it is easy to implement and maintains order integrity. Single picking performs well with a small number of orders and a high number of picks per order. Picking orders with small number of picks (per order) will lead to an excessive travel time. Picking many orders with small numbers of picks will cause congestion situations - many pickers simultaneously working in the same area will slow down a picking process. 
In batch picking several orders are batched (grouped) together. Pickers pick all items (from a given batch) in a single pick-tour. Batch usually includes a few to several orders. It depends on the average number of picks per order and a size of picked items. Batch picking systems may use complex logics which are useful for consolidated orders.

Zone picking is a policy that divides order picking area into zones. Pickers retrieve items (SKUs) only within a single zone. This strategy requires additional operations to consolidate orders picked in different zones. Batching and zoning strategies can also be combined (zonebatch picking). In such situation each picker needs to pick items from different pick lists prepared for particular areas.

In each of these strategies orders (from customers) can be fulfilled by different employees simultaneously. Assigning orders to the relevant time window is usually dictated by the time of their appearing in system or the time till which they have to be fulfilled (to send them to customers on time).

As mentioned, simultaneous picking by many pickers may give rise to phenomenon of "pickers blocking". It occurs when work performed by one picker is disturbed by another one (see Fig. 1). Congestion situations lead to time loss. This is due to the fact that pickers have to wait for the opportunity to continue their picking processes. In manual order picking systems - ,picker to parts” - blocking (congestion) situations may occur when:

- all pickers start or finish picking near to a depot (Fig. 1 - situation $\mathbf{C}$ ),

- at cross aisles (Fig. 1 - situations A, C, G),

- at pick aisles and sub aisles (Fig. 1 - situations D, E, F).
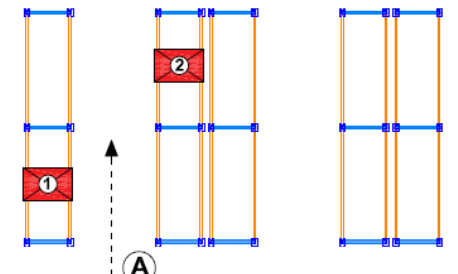

(1)
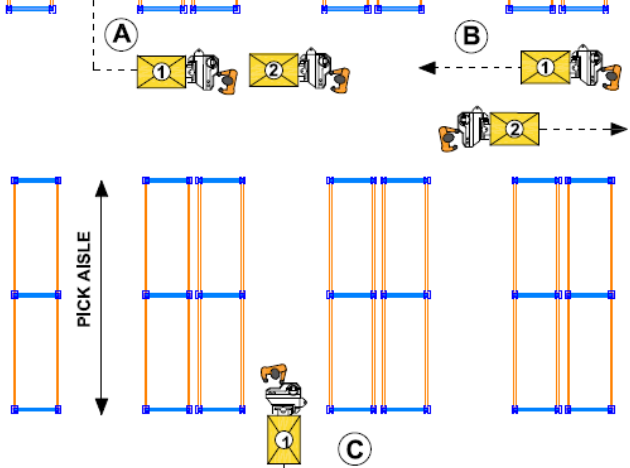

(2)

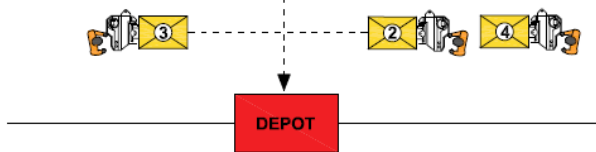

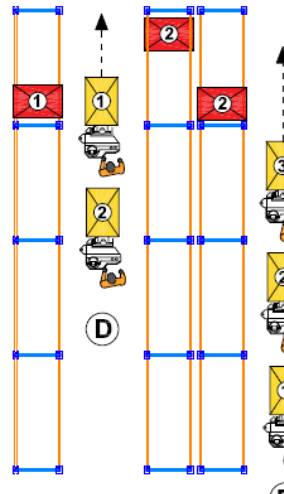

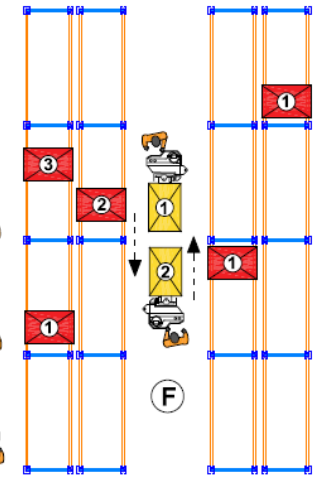

(E)

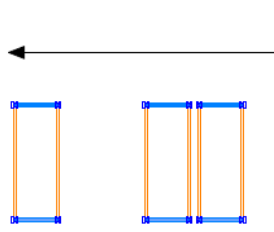

CROSS AISLE
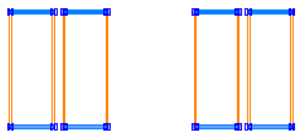
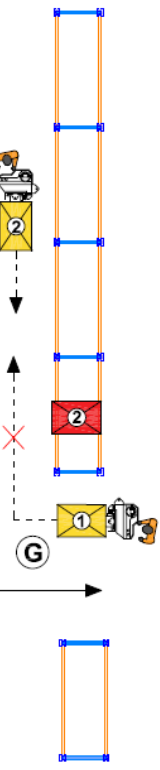

Figure 1: Examples of a pickers blocking in order picking area.

In the first case, pickers are receiving orders at the same time. So, they are able to start picking at the same moment. It may cause disruption of unconstrained workers movement near to the depot area. A similar situation can occur when more than one picker finish the process and put away a mixed unit load (Fig. 1 - situation $\mathbf{C}$ ).

In most cases, cross aisles of order picking area are not wide enough to enable pickers passing each other. However, very often it is assumed that in cross aisles, pickers can pass each other only when they are moving in opposite directions (Fig. 1 - situation B). If they are moving in the same direction, they will move sequentially, one after another (Fig. 1 - 
situation A). Such assumptions lead to pickers' speed limitations in cross aisles, hence these assumptions can significantly increase safety in order picking area.

Pickers blocking may also appear in the narrow pick aisles. Fig. 1 shows four examples of such situations (Fig. 1 - situation D-G). In the first case, picker No. 1 is picking items and blocking picker No. 2 at the same time (picker No. 2 can't reach his picking location). Similar situation is shown in Fig. 1 - situation E, where pickers No. 1 and 2 are both being blocked by the third one.

Other example of pickers blocking phenomenon is when pickers are moving in opposite directions in pick aisles (Fig. 1 - situation F). That situation requires from one of picker to change his move direction and leave an aisle from the other side than he was about to. It results in longer picking path, additional loss of time as well as increasing duration of an entire order picking process.

In the last example (Fig. 1 - situation G) picker No. 2 sees another worker in pick aisle that he was going to visit. In that situation picker No. 2 does not enter this aisle, but waits for a moment when it will be released. It avoids situation that one of the pickers must retreat to release the aisle for the next one. Additionally, simultaneous work of two and more picking trucks (high-level vertical order picking trucks) in one pick aisle could be forbidden because of safety rules.

\section{STORAGE ASSIGNMENT}

A storage assignment policy (SAP) is a set of rules used to assign products (SKUs, items) to storage locations. The following storage assignments methods are used: random, closestopen-location, volume-based (a type of dedicated storage assignment), class-based, familygrouping, etc.

Random storage assignment allocates SKUs randomly over available storage locations. This method is very often used as a benchmark to compare different assignments methods.

Closest-open-location method is a variation of random policy. It allocates all incoming items (SKUs) to the closest and still empty storage locations. This is one of the simplest methods used when employees have to select storage locations (when put-away/replenishment operations are not directed by WMS). The first encountered empty location is the potential place for the item storage. This policy has been widely discussed in [21].

Volume-based storage assignment uses dedicated locations. This method usually assigns each SKU to storage location according to the expected pick volume, so each type of items has a fixed storage place. The pick volume of SKU can be measured by number of unit loads (pallets, boxes), number of items or pick lines picked in certain time. Frequently picked items are located close to depot. SKUs can be assigned to locations also according to another criterion such as pick regularity.

Family-grouping storage assignment is a variant of dedicated methods. It is based on the idea that similar products are located in the same space of the storage area. For example, SKUs that usually appear together in the same pick orders, or are usually picked in the same pick-tour, should be stored close to each other. Another reason for that can be the same supplier or the same owner. To apply family grouping a correlation between SKUs should be known (or at least should be predictable), e.g. frequency at which they appear together in the order (see [22]).

Another dedicated storage assignment method is the cube-per-order index (COI method) [21]. The method assigns items to storage locations according to COI parameter which is defined as the ratio of the total space required for SKU and the number of trips required to satisfy its demand per period. Items with the lowest $C O I$ are located closest to the depot. For more details see [23-25]. 
Class-based assignment is a combination of random and dedicated methods. It bases on items grouping (clustering), and divides both the SKUs and the storage locations into the same number of classes. Items to classes assignment is based on parameters such as, e.g.: pick volume, pick frequency or pick regularity (XYZ method). Storage locations are divided into clusters (classes) usually according to the distance from the depot. Next, classes of SKU and locations are sorted (SKUs in decreasing order and storage location in increasing order) and then combined in that order. Usually, number of SKU classes is limited to three and each of them named respectively $\mathrm{A}, \mathrm{B}$ and $\mathrm{C}$ or $\mathrm{X}, \mathrm{Y}$ and $\mathrm{Z}$ (the first class collects the fastest moving items or the most regular, while the last class collects the slowest or the most irregular). Using more than three classes is of course possible but with a number of classes also space requirements increases (effect of the fixed storage locations for stock of materials in classes). For more information about class-based assignment as well as its impact on layout of storage area see [26].

Numerous methods are used to assign items to locations. Each of them can affect pick paths lengths, picking time and congestion. Selecting storage assignment method for particular order picking system is one of the crucial steps to obtain expected order picking efficiency.

The influence of storage assignment on congestion and pickers blocking (see $[10,11]$ ) is not widely considered in the literature, but these issues are strongly correlated. The situation when the most frequently picked items are located in the same, closest aisle will make pickers visiting that aisle often at the same time and will result in congestion and delays. Therefore, we investigate, which storage assignment method brings the lowest time losses (due to congestion) over specific order picking conditions (related to specific number of pickers, picking strategy or routing method).

\section{EVALUATION OF PICKING PROCESS}

The picking list is generated according to customers' orders. As a result, mixed unit loads (consisting of more than single SKUs) are prepared. Formal presentation of order picking evaluation criteria required defining the following sets: set of pickers $\boldsymbol{O P}$ ( $o p$ is the number of an order picker), set of all picking lists $\boldsymbol{P L}$ ( $p l$ is the number of a picking list), set of picking lists assigned to picker $\boldsymbol{P} \boldsymbol{L}^{\boldsymbol{o p}}$, set of types of picked articles (SKUs) $\boldsymbol{G}$ ( $g$ is the number of an item type), and a set of rows in a given picking list $\boldsymbol{L R}^{\boldsymbol{p l}}$.

It was also assumed that, the order picking process time is a period between the receiving of the first picking list and putting off the last prepared mixed unit load at the depot. To determine the time of picking of all picking lists, it is necessary to determine beginning $\left(t^{s}(o p, p l)\right)$ and ending process $\left(t^{e}(o p, p l)\right)$ moments for all pickers [17]. These moments should be placed on the timeline. Next, the earliest moment of beginning and the latest moment of ending picking of each picker can be determined. Time duration between these two moments defines the time of all picking list fulfilment (see Fig. 2). It was presented as Eq. (1).

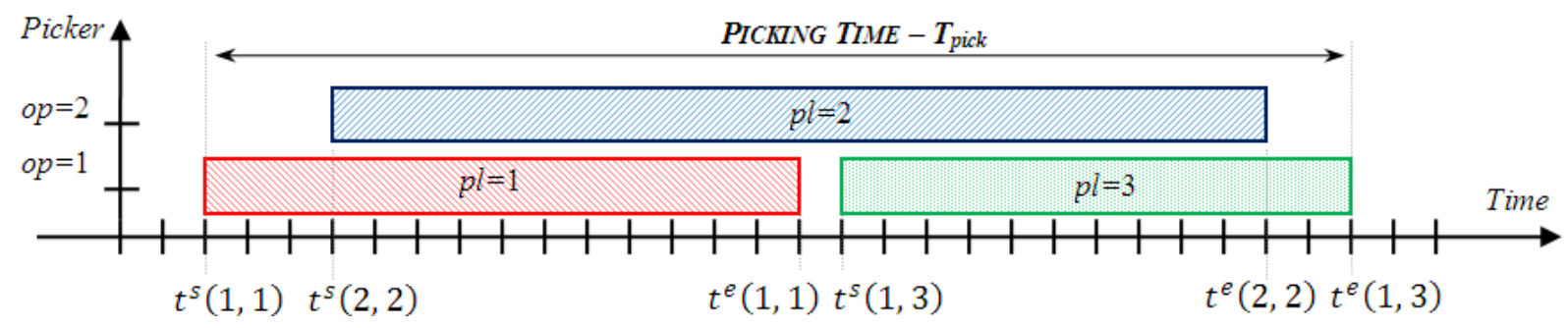

Figure 2: Moments of the beginning and ending of fulfilling individual picking lists 
The moment when picking of particular list is completed can be determined by the Eq. (2). It is a sum of picking beginning moment and a period in which picking list was fulfilled. Time of an individual picking list fulfilment by individual picker can be determined by Eq. (3). Components used in this formula are as follows: $\Delta t^{r}(o p, p l)$ - travel time of order picker $o p$ during picking list $p l$ fulfilment; $\Delta t^{p}(o p, p l)$ - picking time (reaching and placing items to load carrier) by order picker $o p$ during picking list $p l$ fulfilment; $\Delta t^{w}(o p, p l)$ - picker $o p$ waiting time during picking list $p l$ fulfilment (time when picker is blocked and can't continue pickings).

Usually the efficiency of order picking process is measured by the number of orders, lines or SKU items fulfilled or picked per time unit. In case of the orders number, the efficiency can be determined as presented in Eq. (4). We assumed, that $\sigma(p l, o p)=1$ when picker $o p$ is assigned to picking list $p l$. Otherwise, $\sigma(p l, o p)=0$. In case when order picking efficiency is evaluated by the number of lines (rows of picking list) picked in a unit of time, we can use Eq. (5). Designation $\xi(p l)$ in Eq. (5) is the total number of rows (lines) that list $p l$ contains. If a single line is defined as a single picked item, then order picking efficiency would be presented as a number of items picked per unit time, see Eq. (6). Designation $\omega(\mu(p l), g)$ in Eq. (6) is the number of $g$-type items picked in a row $\mu(p l)$ of a picking list $p l$.

Order picking process can be also evaluated using the efficiency of individual pickers or pickers working time utilization. In this paper we assumed, that efficiency of the operator $o p$ is measured by a number of his picked items in a unit of time. It can be formulated as it is presented in Eq. (7). Work time utilization of the picker op is a ratio of his undisturbed working time (working time that do not include time when picker has to wait or is blocked) and a total of his picking time. Picker working time utilization can be formulated as Eq. (8).

For more information about Eqs. (1) to (8) see [17].

$$
\begin{aligned}
& T_{p i c k}=\max _{o p \in \boldsymbol{O P}, p l \in \boldsymbol{P L}}\left\{t^{e}(o p, p l)\right\}-\min _{o p \in \boldsymbol{O P}, p l \in \boldsymbol{P L}}\left\{t^{s}(o p, p l)\right\} \\
& t^{e}(o p, p l)=t^{s}(o p, p l)+\Delta t(o p, p l) \forall_{o p \in \boldsymbol{O P}, p l \in \boldsymbol{P} \mathbf{L}^{o p}} \\
& \Delta t(o p, p l)=\Delta t^{r}(o p, p l)+\Delta t^{p}(o p, p l)+\Delta t^{w}(o p, p l) \forall_{o p \in \boldsymbol{O P}, p l \in \boldsymbol{P} \mathbf{L}^{o p}} \\
& W_{\text {pick }}=\frac{\sum_{o p \in \boldsymbol{O P}} \sum_{p l \in \boldsymbol{P} \boldsymbol{L} \boldsymbol{o p}} \sigma(o p, p l)}{\max _{o p \in \boldsymbol{O P}, p l \in \boldsymbol{P L}}\left\{t^{e}(o p, p l)\right\}-\min _{o p \in \boldsymbol{O P}, p l \in \boldsymbol{P L}}\left\{t^{S}(o p, p l)\right\}} \\
& W_{p i c k}=\frac{\sum_{o p \in \boldsymbol{O P}} \sum_{p l \in \boldsymbol{P L}} \boldsymbol{o p} \sigma(o p, p l) \xi(p l)}{\max _{o p \in \boldsymbol{O P}, p l \in \boldsymbol{P} \mathbf{L}}\left\{t^{e}(o p, p l)\right\}-\min _{o p \in \boldsymbol{O P}, p l \in \boldsymbol{P L}}\left\{t^{s}(o p, p l)\right\}}
\end{aligned}
$$

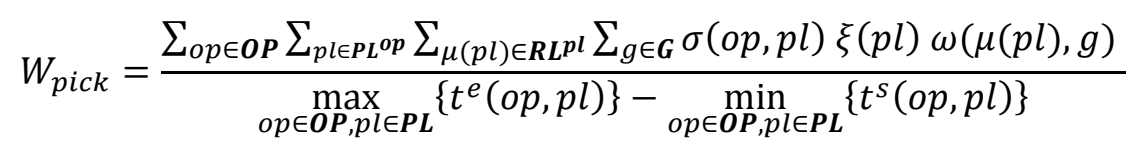

$$
\begin{aligned}
& W_{p i c k}(o p)=\frac{\sum_{p l \in \boldsymbol{P L}}{ }^{o p} \sum_{\mu(p l) \in \boldsymbol{R} L^{p l}} \sum_{g \in \boldsymbol{G}} \xi(p l) \omega(\mu(p l), g)}{\max _{o p \in \boldsymbol{O P}, p l \in \boldsymbol{P L}^{\boldsymbol{o p}}}\left\{t^{e}(o p, p l)\right\}-\min _{o p \in \boldsymbol{O P}, \boldsymbol{P} \mathbf{L}^{\boldsymbol{o p}}}\left\{t^{S}(o p, p l)\right\}} \\
& P T U(o p)=\frac{\sum_{p l \in \boldsymbol{P} L^{o p}} \Delta t(o p, p l)+\Delta t^{w}(o p, p l)}{\sum_{p l \in \boldsymbol{P L}} \boldsymbol{o p}^{o p} \Delta t(o p, p l)} 100 \% \forall_{o p \in \boldsymbol{O P}}
\end{aligned}
$$

\section{ASSUMPTIONS FOR MODEL OF ORDER PICKING SYSTEM}

To simulate and evaluate variants of the order picking process the model of order picking system was developed. The main model assumptions are presented below:

- order picking is performed in a bulk-storage area according to the manual-picker-to-part method, 
- pickers use Narrow Aisle Order Picker Trucks (items are retrieved - picked- from all possible storage levels, order picking area includes narrow pick aisles),

- picking area uses pallet racks with a total storage capacity of 2160 pallets,

- picking area is composed of 3 storage blocks and 9 pick aisles (see Fig. 3),

- each rack consists of 8 bays and 5 storage levels (see Fig. 3),

- depot is located in front of the leftmost pick aisle (see Fig. 3),

- pickers can't turn back and pass each other in pick aisles,

- if a pick aisle is occupied by a picker that is moving towards the other picker that is entering that aisle, then entering picker must wait till an aisle is available (see Fig. 1 situation $\mathbf{G})$,

- pickers that are moving the same direction cannot pass each other in cross aisle,

- order picking area replenishment is not considered (doesn't influence congestion),

- S-shape routing policy is used,

- horizontal velocity of order picking truck is $0,97 \mathrm{~m} / \mathrm{s}$, and vertical velocity is $0,25 \mathrm{~m} / \mathrm{s}$,

- time of single item picking up is 4,5 s,

- 200 order lines are processed into pick lists to be fulfilled in order picking process,

- pick lists are generated on the base of historical (annual) orders,

- both, the single picking and the batch picking strategies are used,

- 3, 6, 9 or 12 pickers are engaged,

- in case of batch picking, pick lists are assigned to pickers according to the criterion of equal workload - number of items to be picked by each picker is the same or quite similar,

- different variations of three basic storage policies: random, class-based and volume-based are used.

As mentioned in a list of assumptions, variations of three basic storage policies: random assignment, class-based assignment and volume-based assignment were applied in model. In the class-based policies (ABC, XYZ) SKUs were divided into three subsets (classes) according to such parameters as: pick frequency - ABC1, pick volume - ABC2 and pick regularity - XYZ. The same parameters were used to volume-based methods: pick frequency - VOL1, pick volume - VOL 2, pick regularity - VOL3 (see Table I). Additionally, storage locations were ranked according to different criteria (ranks determine the order of SKUs assignment to locations), such as: access time from the depot (R1), distance from the depot (R2), the closest pick aisle and the access time from the depot to location (R3), the closest pick aisle and distance from the depot to location (R4). In the $\mathbf{R 3}$ and the $\mathbf{R 4}$ methods, firstly are ranked pick aisles according to distance from the depot, then storage locations they include.

As a result, 25 different storage assignments methods were configured (see Table II). For example, ABC1R1 means that SKUs were assigned to classes according to the method ABC1 (using pick frequency parameter) and storage locations were ranked according to the access time from the depot $(\mathbf{R 1})$.

Table I: Types of storage assignment methods.

\begin{tabular}{|c|c|c|c|c|c|c|c|}
\hline \multirow{2}{*}{ SAP } & Random & \multicolumn{3}{|c|}{ Class-based } & \multicolumn{3}{c|}{ Volume-based } \\
\cline { 2 - 7 } & Ran & ABC1 & ABC2 & XYZ & VOL1 & VOL2 & VOL3 \\
\hline $\begin{array}{c}\text { Rank } \\
\text { parameter }\end{array}$ & - & $\begin{array}{c}\text { Pick } \\
\text { frequency } \\
\text { [times/year] }\end{array}$ & $\begin{array}{c}\text { Pick } \\
\text { volume } \\
\text { [units/year] }\end{array}$ & $\begin{array}{c}\text { Pick } \\
\text { regularity }\end{array}$ & $\begin{array}{c}\text { Pick } \\
\text { frequency } \\
\text { [times/year] }\end{array}$ & $\begin{array}{c}\text { Pick } \\
\text { volume } \\
\text { [units/year] }\end{array}$ & $\begin{array}{c}\text { Pick } \\
\text { regularity }\end{array}$ \\
\hline
\end{tabular}

Basing on above assumptions, 150 variants of the order picking system were generated, picking process was simulated and basic measures of process effectiveness were calculated. 
The algorithm for generating pick lists was developed. Algorithm analyses a structure of historical orders (how often each SKU was ordered, what was order quantity, who ordered, etc.) and then generates order lines and processes them into pick lists. Assignment of order lines to a particular pick list is dependent on who was ordering (if a single pick strategy is used) and what was the maximal acceptable weight and volume of all items picked in one tour (capacity of carrier). The same historical data were used for storage assignment methods, therefore generated pick lists can be used for evaluation of these methods (simulation).

\section{SIMULATOR OF ORDER PICKING PROCESS}

To simulate order picking process SimPick application was developed (see Fig. 3). Its main function is to allow researcher to shape, design and organize "picker-to-part" order picking system. SimPick application allows for: external data import, designing and organizing order picking system, order picking process simulation and results display and export.

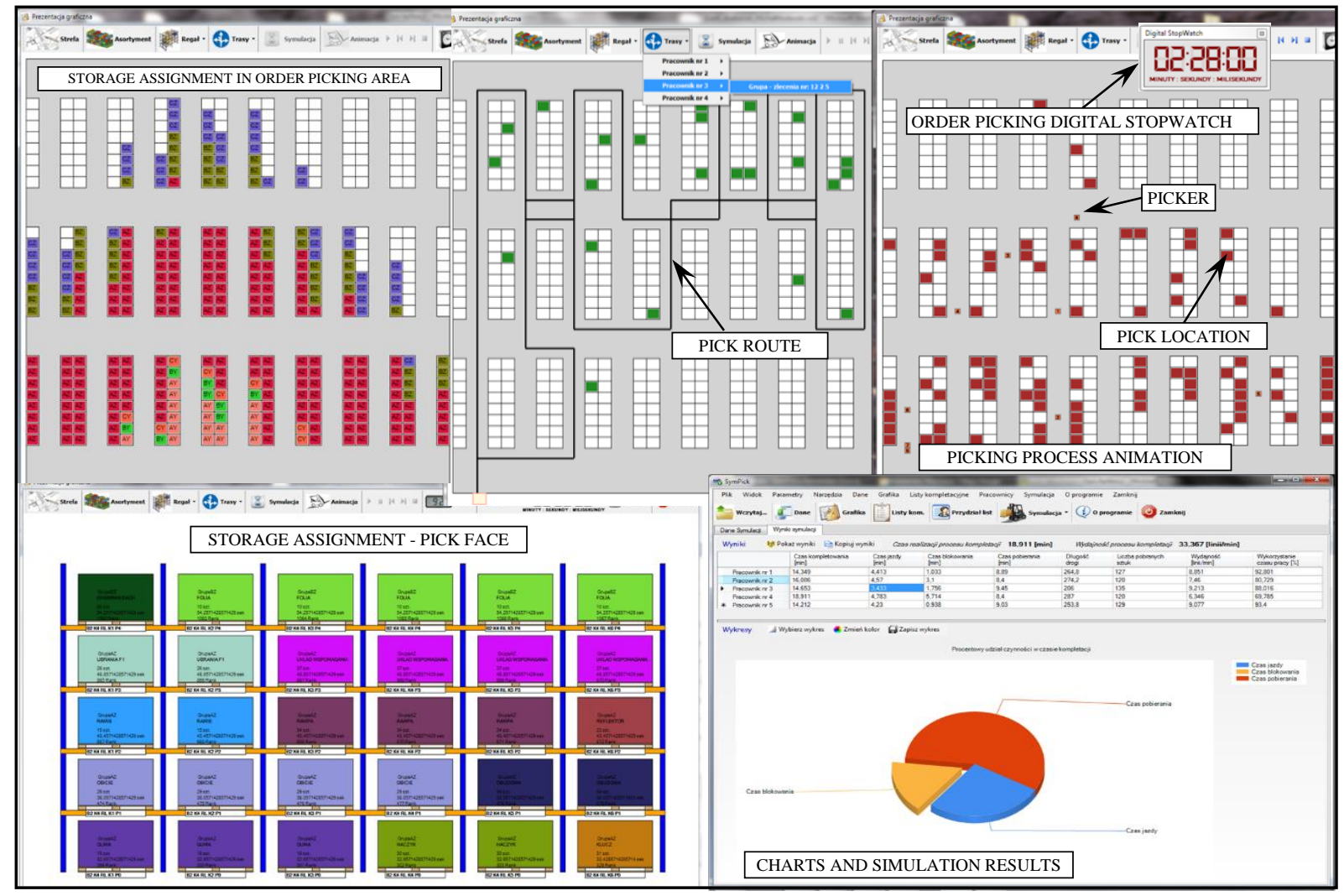

Figure 3: Selected screens of SimPick.

The module of designing and organization of an order picking allows to: design order picking area layout, storage assignment, generating and batching order picking lists, selection of the number of picker used to order picking, allocation of picking lists to individual pickers and routing (determining pick routs). This module requires also data as e.g.: parameters of uniform and mixed pallet units $\left(\mathrm{kg}, \mathrm{m}^{3}\right)$, dimensions of pick locations, pick and cross aisles etc.

Order picking simulation module allows calculating and analysing all activities performed by pickers. The algorithm monitors current status of all pickers (e.g. traveling, picking up, blocked) and calculates that status duration. The given status time is used to estimate total order picking time. Simplified form of algorithm for each pickier is presented below: 

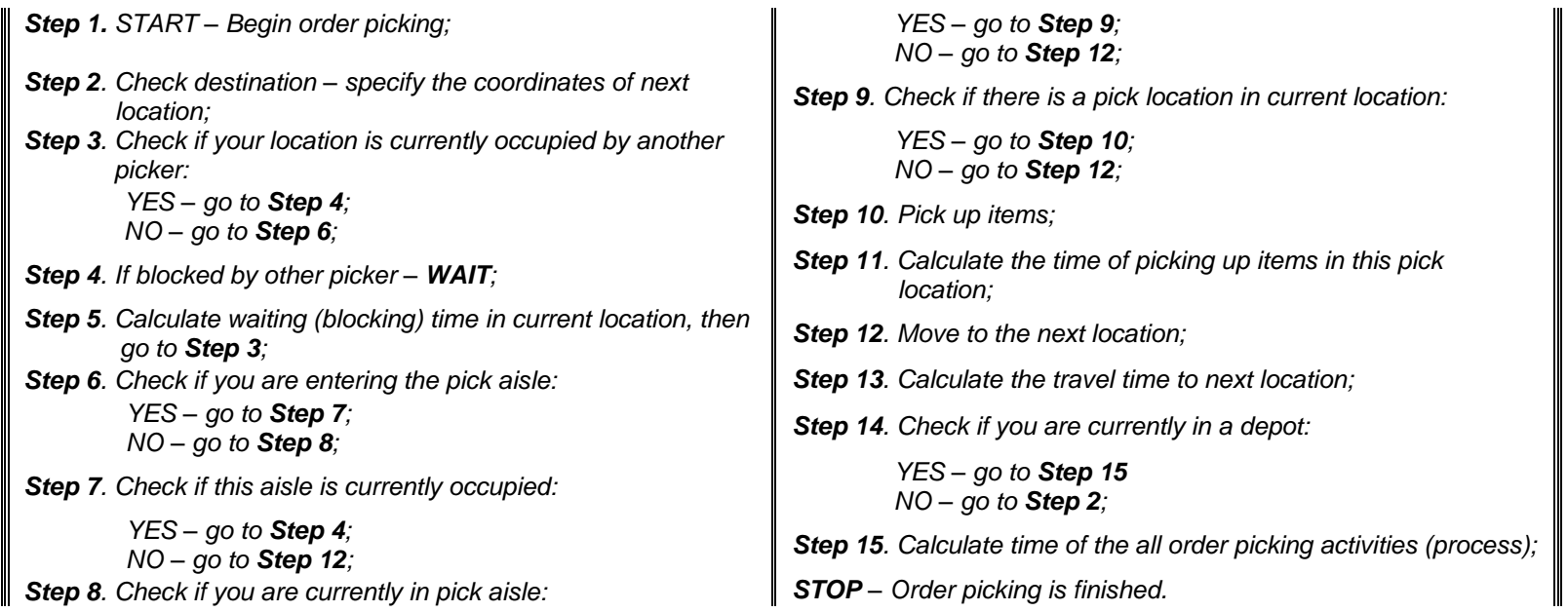

As a result of the simulation, individual activities of every picker (e.g. picking time, free ride time, blocking time), time of picking lists fulfilment, order picking efficiency, individual order pickers productivity, individual order pickers time utilization, etc. were determined. Thanks to these results, the congestion in order picking area could be specified.

The last module is used for graphical and tabular presentation of results and their export to external files. It allows displaying: order picking area layout, storage assignment in this area, slotting results in pick faces, presentation of picking routes, and order picking process animation (see Fig. 3). All external data loaded into the application, generated order picking lists, as well as results of analysis and simulation can be presented in a tabular form.

\section{SIMULATION RESULTS}

All variants of order picking system described in chapter 5 were modelled in SimPick and used to simulate order picking processes. Results of simulations are presented in Table II and in Fig. 4.

The comparison of variants presented in Fig. 4 and in Table II shows that the most efficient variant was characterized by: volume-based assignment policy according to pick volume (units per year), storage locations ranking according to the closest pick aisle and access time from the depot, 9 pickers and discrete picking strategy (VOL2R3). The worst variant was the one characterized by: class-based assignment according to pick volume (units per year), storage locations rank according to the distance from the depot, 3 picking workers and batch picking strategy (ABC2R2).

Simulations results show that order picking efficiency is directly correlated with the number of pickers (see Fig. 4). With the increasing number of workers also the process efficiency increases, but it causes the lower growth in efficiency too. It is related to congestion situations in the order picking area. Regardless of storage assignment as well as picking method, the blocking time always increases with the number of pickers (see Table II). Therefore, the correlations between congestion situations and picking organisation should be considered.

In both, single and batch picking variants, volume-based methods were more efficient than class-based (ABC) methods. Analyses show that order picking variants with volume-based methods were characterised by shorter picking times and pickers blocking times. However, they had the longer free ride times, which mean that picking paths were also longer. It is connected to the number of storage units per SKU that are offered in order picking area. Inventory data used in simulation indicate that there were many units per particular SKU. Thus, in consequence, it led to the less pick density in aisles (no more than few different SKUs were located in every pick aisle) and less congestion. On the other hand, pickers had to 
visit more aisles, what extended the pick paths. Within each class in ABC methods, SKUs are assigned to storage locations randomly. So, many different SKUs can be offered in one particular aisle. It provided shortening picking paths as well as a congestion increase (e.g. the fast moved SKUs are offered only in one aisle).

Table II: Results of the order picking simulation in selected variants of the order picking system.

\begin{tabular}{|c|c|c|c|c|c|c|c|c|c|c|c|c|c|c|c|}
\hline \multirow{5}{*}{ SAP } & \multicolumn{15}{|c|}{ NUMBER OF PICKERS } \\
\hline & \multicolumn{5}{|c|}{3} & \multicolumn{5}{|c|}{6} & \multicolumn{5}{|c|}{9} \\
\hline & $O P T$ & $F R T$ & $B T$ & $P T$ & $P T U$ & $O P T$ & $F R T$ & $B T$ & $P T$ & $P T U$ & $O P T$ & $F R T$ & $B T$ & $P T$ & $P T U$ \\
\hline & [min] & [min] & [min] & [min] & {$[\%]$} & [min] & [min] & [min] & [min] & {$[\%]$} & [min] & [min] & [min] & [min] & {$[\%]$} \\
\hline & \multicolumn{15}{|c|}{ SINGLE PICK } \\
\hline RAN & 37,29 & 12,05 & 1,86 & 23,38 & 95,11 & 21,49 & 5,86 & 3,94 & 11,69 & 82,29 & 15,63 & 3,98 & 3,86 & 7,79 & 78,89 \\
\hline ABC1R1 & 34,67 & 10,61 & 0,68 & 23,38 & 97,96 & 19,01 & 5,3 & 2,02 & 11,69 & 88,96 & 14,97 & 3,53 & 3,65 & 7,79 & 77,7 \\
\hline ABC1R2 & 35,32 & 9,6 & 2,34 & 23,38 & 93,77 & 19,16 & 4,8 & 2,67 & 11,69 & 87,24 & 14,6 & 3,2 & 3,61 & 7,79 & 78,4 \\
\hline ABC1R3 & 35,51 & 10 & 2,13 & 23,38 & 94,5 & 20,87 & 5 & 4,18 & 11,69 & 80,73 & 17,74 & 3,33 & 6,62 & 7,79 & 65,88 \\
\hline ABC1R4 & 37,11 & 9,57 & 4,16 & 23,38 & 89,41 & 21,91 & 4,78 & 5,44 & 11,69 & 75,37 & 18,61 & 3,19 & 7,63 & 7,79 & 63,02 \\
\hline ABC2R1 & 37,11 & 10,44 & 3,29 & 23,38 & 92,05 & 20,4 & 5,22 & 3,49 & 11,69 & 83,49 & 16,25 & 3,48 & 4,98 & 7,79 & 70,09 \\
\hline ABC2R2 & 33,88 & 9,81 & 0,69 & 23,38 & 97,94 & 20,79 & 4,84 & 4,26 & 11,69 & 80,32 & 14,69 & 3,18 & 3,72 & 7,79 & 76,23 \\
\hline ABC2R3 & 35,31 & 9,66 & 2,27 & 23,38 & 93,65 & 21,84 & 4,83 & 5,32 & 11,69 & 75,89 & 15,98 & 3,22 & 4,97 & 7,79 & 68,81 \\
\hline ABC2R4 & 35,4 & 9,64 & 2,38 & 23,38 & 93,38 & 21,61 & 4,82 & 5,1 & 11,69 & 78,91 & 15,01 & 3,21 & 4,01 & 7,79 & 73,34 \\
\hline XYZR1 & 35,08 & 10,25 & 1,45 & 23,38 & 95,97 & 19,37 & 5,12 & 2,56 & 11,69 & 88,65 & 14,55 & 3,42 & 3,34 & 7,79 & 79,72 \\
\hline XYZR2 & 34,84 & 9,94 & 1,52 & 23,38 & 95,66 & 20,13 & 4,97 & 3,47 & 11,69 & 82,75 & 15,34 & 3,31 & 4,24 & 7,79 & 75,81 \\
\hline XYZR3 & 35,42 & 9,62 & 2,42 & 23,38 & 93,28 & 19,83 & 4,81 & 3,33 & 11,69 & 85,06 & 13,92 & 3,21 & 2,92 & 7,79 & 81,15 \\
\hline XYZR4 & 34,62 & 9,13 & 2,11 & 23,38 & 94,2 & 19,49 & 4,57 & 3,23 & 11,69 & 84,25 & 15,62 & 3,04 & 4,79 & 7,79 & 72,27 \\
\hline Vol1R1 & 37,05 & 11,26 & 2,41 & 23,38 & 93,49 & 19,48 & 5,63 & 2,16 & 11,69 & 89,1 & 15,98 & 3,75 & 4,44 & 7,79 & 74,19 \\
\hline Vol1R2 & 35,71 & 10,02 & 2,31 & 23,38 & 93,5 & 19,88 & 5,01 & 3,18 & 11,69 & 84,71 & 17,04 & 3,37 & 5,88 & 7,79 & 68,86 \\
\hline Vol1R3 & 35,51 & 10,31 & 1,82 & 23,38 & 94,9 & 20,03 & 5,15 & 3,19 & 11,69 & 84,61 & 15,26 & 3,44 & 4,03 & 7,79 & 74,03 \\
\hline Vol1R4 & 34,63 & 10,08 & 1,17 & 23,38 & 96,74 & 20,02 & 5,04 & 3,29 & 11,69 & 83,78 & 14,83 & 3,36 & 3,68 & 7,79 & 75,16 \\
\hline Vol2R1 & 36,99 & 11,41 & 2,2 & 23,38 & 94,22 & 19,86 & 5,7 & 2,47 & 11,69 & 87,46 & 14,93 & 3,8 & 3,34 & 7,79 & 79,98 \\
\hline Vol2R2 & 34,68 & 10,19 & 1,11 & 23,38 & 96,7 & 18,89 & 4,95 & 2,25 & 11,69 & 88,57 & 17,04 & 3,37 & 5,88 & 7,79 & 68,86 \\
\hline Vol2R3 & 34,52 & 10,14 & 1 & 23,38 & 97,15 & 19,85 & 5,07 & 3,09 & 11,69 & 84,14 & 14,6 & 3,38 & 3,43 & 7,79 & 76,29 \\
\hline Vol2R4 & 35,3 & 10,29 & 1,63 & 23,38 & 95,55 & 21,17 & 5,14 & 4,34 & 11,69 & 79,49 & 15,05 & 3,29 & 3,97 & 7,79 & 76,62 \\
\hline Vol3R1 & 35,95 & 11,3 & 1,27 & 23,38 & 96,55 & 20,53 & 5,65 & 3,19 & 11,69 & 85,55 & 15,34 & 3,77 & 3,78 & 7,79 & 78,53 \\
\hline Vol3R2 & 34,47 & 10,01 & 1,08 & 23,38 & 97,11 & 20,09 & 5 & 3,4 & 11,69 & 84,16 & 14,31 & 3,34 & 3,18 & 7,79 & 79,8 \\
\hline Vol3R3 & 34,03 & 9,7 & 0,95 & 23,38 & 97,31 & 19,15 & 4,85 & 2,61 & 11,69 & 87,07 & 15,21 & 3,45 & 3,97 & 7,79 & 73,92 \\
\hline \multirow[t]{2}{*}{ Vol3R4 } & 35,73 & 10,46 & 1,89 & 23,38 & 95,16 & 20,48 & 5,23 & 3,56 & 11,69 & 82,29 & 15,45 & 3,49 & 4,17 & 7,79 & 73,19 \\
\hline & \multicolumn{15}{|c|}{ ORDER BATCHING } \\
\hline RAN & 32,3 & 5,2 & 3,72 & 23,38 & 89,41 & 19,36 & 4,18 & 3,49 & 11,69 & 83,47 & 14,54 & 3,33 & 3,42 & 7,79 & 79,68 \\
\hline ABC1R1 & 35,3 & 5,3 & 6,62 & 23,38 & 82,37 & 18,59 & 3,86 & 3,04 & 11,69 & 84,11 & 14,9 & 3 & 4,11 & 7,79 & 73,86 \\
\hline ABC1R2 & 30,5 & 4,56 & 2,56 & 23,38 & 91,91 & 19,31 & 3,28 & 4,34 & 11,69 & 79,39 & 15,04 & 2,7 & 4,55 & 7,79 & 72,94 \\
\hline ABC1R3 & 31,39 & 4,49 & 3,52 & 23,38 & 90,35 & 20,29 & 3,47 & 5,13 & 11,69 & 77,68 & 17,25 & 2,75 & 6,71 & 7,79 & 62,3 \\
\hline ABC1R4 & 34,32 & 4,38 & 6,56 & 23,38 & 81,96 & 20,13 & 3,32 & 5,12 & 11,69 & 77,7 & 17,17 & 2,65 & 6,73 & 7,79 & 63,98 \\
\hline ABC2R1 & 35,78 & 4,96 & 7,44 & 23,38 & 81,82 & 20,61 & 3,77 & 5,15 & 11,69 & 79,81 & 16,04 & 3,05 & 5,2 & 7,79 & 68,99 \\
\hline $\mathrm{ABC2R2}$ & 34,75 & 4,48 & 6,89 & 23,38 & 83,62 & 18,00 & 3,61 & 2,7 & 11,69 & 86,99 & 14,55 & 2,83 & 3,93 & 7,79 & 75,18 \\
\hline ABC2R3 & 32,74 & 4,46 & 4,9 & 23,38 & 86,7 & 20,72 & 3,4 & 5,63 & 11,69 & 74,87 & 17,44 & 2,81 & 6,84 & 7,79 & 61,7 \\
\hline ABC2R4 & 31,63 & 4,46 & 3,79 & 23,38 & 89,29 & 19,43 & 3,32 & 4,42 & 11,69 & 78,98 & 16,56 & 2,86 & 5,91 & 7,79 & 64,56 \\
\hline XYZR1 & 32,39 & 4,98 & 4,03 & 23,38 & 88,35 & 18,27 & 3,75 & 2,83 & 11,69 & 85,7 & 14,06 & 2,94 & 3,33 & 7,79 & 78,25 \\
\hline XYZR2 & 31,27 & 4,65 & 3,24 & 23,38 & 90,65 & 20,28 & 3,47 & 5,12 & 11,69 & 77,1 & 16,01 & 2,75 & 5,47 & 7,79 & 69,05 \\
\hline XYZR3 & 31,46 & 4,67 & 3,41 & 23,38 & 90,22 & 18,84 & 3,3 & 3,85 & 11,69 & 81,12 & 16,06 & 2,71 & 5,56 & 7,79 & 66,83 \\
\hline XYZR4 & 31,78 & 4,35 & 4,05 & 23,38 & 88,55 & 19,56 & 3,18 & 4,69 & 11,69 & 77,04 & 16,44 & 2,56 & 6,09 & 7,79 & 64,09 \\
\hline Vol1R1 & 33,77 & 5,5 & 4,89 & 23,38 & 87,09 & 22,47 & 4,16 & 6,62 & 11,69 & 73,02 & 17,36 & 3,3 & 6,27 & 7,79 & 65,87 \\
\hline Vol1R2 & 34,12 & 4,49 & 6,25 & 23,38 & 83,83 & 20,37 & 3,47 & 5,21 & 11,69 & 76,85 & 15,91 & 2,87 & 5,25 & 7,79 & 69,8 \\
\hline Vol1R3 & 31,74 & 4,85 & 3,51 & 23,38 & 89,93 & 17,99 & 3,44 & 2,86 & 11,69 & 85,29 & 14,34 & 2,8 & 3,75 & 7,79 & 78,97 \\
\hline Vol1R4 & 31,07 & 4,66 & 3,03 & 23,38 & 91,13 & 19,74 & 3,58 & 4,47 & 11,69 & 77,61 & 15,65 & 2,99 & 4,87 & 7,79 & 69,16 \\
\hline Vol2R1 & 33,96 & 5,65 & 4,93 & 23,38 & 85,42 & 20,7 & 4,15 & 4,86 & 11,69 & 77,53 & 15,42 & 3,36 & 4,27 & 7,79 & 74,63 \\
\hline Vol2R2 & 32,97 & 4,56 & 5,03 & 23,38 & 86,77 & 22,75 & 3,53 & 7,53 & 11,69 & 71,42 & 13,65 & 2,86 & 3 & 7,79 & 81,34 \\
\hline Vol2R3 & 36,09 & 4,92 & 7,79 & 23,38 & 81,31 & 18,86 & 3,58 & 3,59 & 11,69 & 81,36 & 14,47 & 2,96 & 3,72 & 7,79 & 75,02 \\
\hline Vol2R4 & 34,69 & 4,82 & 6,49 & 23,38 & 83,59 & 21,97 & 3,71 & 6,57 & 11,69 & 70,47 & 16,13 & 3,04 & 5,3 & 7,79 & 68,03 \\
\hline Vol3R1 & 32,75 & 5,51 & 3,86 & 23,38 & 89,26 & 20,6 & 3,98 & 4,93 & 11,69 & 78,82 & 15,71 & 3,25 & 4,67 & 7,79 & 73,2 \\
\hline Vol3R2 & 31,3 & 5,04 & 2,88 & 23,38 & 92,17 & 18,64 & 3,51 & 3,44 & 11,69 & 82,86 & 14,48 & 2,78 & 3,91 & 7,79 & 74,6 \\
\hline Vol3R3 & 32,78 & 4,66 & 4,74 & 23,38 & 87 & 19,32 & 3,65 & 3,98 & 11,69 & 80,32 & 15,06 & 3,03 & 4,24 & 7,79 & 73,23 \\
\hline Vol3R4 & 31,54 & 4,7 & 3,46 & 23,38 & 90,06 & 19,34 & 3,62 & 4,03 & 11,69 & 80,24 & 16,08 & 3,05 & 5,24 & 7,79 & 68,35 \\
\hline
\end{tabular}

( $\boldsymbol{O P T}$ - order picking time, $\boldsymbol{F R T}$ - free ride time, $\boldsymbol{B} \boldsymbol{T}$ - blocking time, $\boldsymbol{P} \boldsymbol{T}$ - picking time, $\boldsymbol{P} \boldsymbol{T} \boldsymbol{U}$ - picker time utilization)

With regard to the impact on congestion, better results were obtained with methods using pick regularity parameter (XYZ, VOL3). This is due to fact that SKUs' regularity has lower impact on blocking situations than their popularity. High SKU picking regularity does not mean that it is picked very often as well. According to these methods, popular SKUs could be scattered among many different aisles. As a consequence, travelled distances were increased 
but pickers' blocking time was decreased significantly. Such effect was noticed for a single and a batch picking.
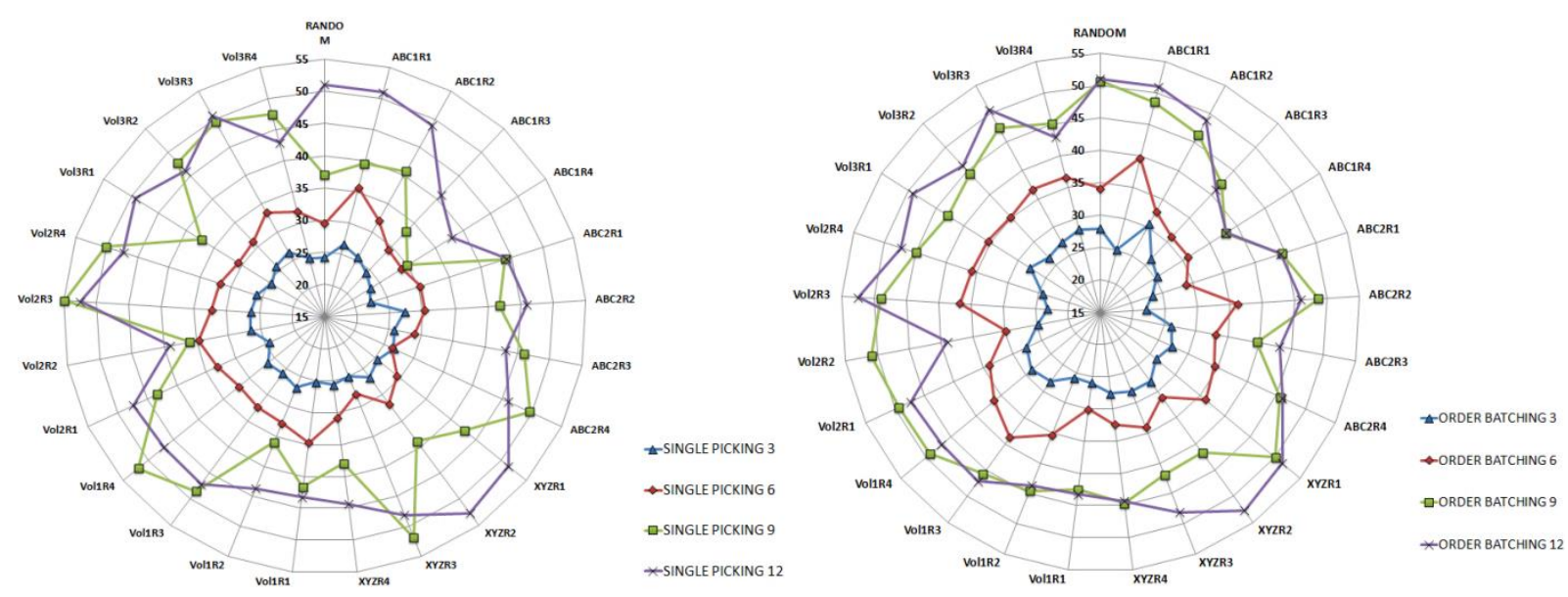

Figure 4: Average order picking productivity for a single picking strategy and a batch picking strategy.

As mentioned in chapter 5, storage locations were ranked according to different criteria (R1-R4). For a single and a batch picking method, the shortest free ride times were for R4 and $\mathbf{R} 2$ criteria (directly related to distance). The longest pick paths were obtained for $\mathbf{R} 1$ criterion (including access time from the depot). Due to the fact that the vertical velocity of order picking truck was few times lower than a horizontal, this criterion usually selects more distant locations for valuable SKUs. Using R3 and R4 criteria resulted in congestion increase (a single and batch picking). Both criteria assign "the most important" SKUs to the closest aisles. Thus, many pickers may want to pick in the same aisle at the same time.

The average share of main activities in order picking process shows the relation between picking strategy, number of pickers and pickers blocking time (Table III). For the variants with the same number of pickers but different picking strategies, the ratio of travel time and picking time was the same or quite similar. As an example see single picking and batch carried out by six pickers (Table III). In both cases travel time (free ride time and blocking time) was about $42 \%$ of whole time of order picking activities. However, in a single picking strategy, travelling time usually dominates over the blocking time. In the case of batch picking, results are quite opposite. It shows that, batch picking leads to longer pickers blocking time than single picking. It is caused by extended pick cycles, larger number of units picked in one cycle, and extended times of blocking pick locations and pick aisles (for a batch picking).

Table III: Average share of main activities in order picking process time.

\begin{tabular}{|c|c|c|c|c|c|c|c|}
\hline Activity & $\begin{array}{c}\text { Single Picking } \\
\mathbf{3}\end{array}$ & $\begin{array}{c}\text { Single Picking } \\
\mathbf{6}\end{array}$ & $\begin{array}{c}\text { Single Picking } \\
\mathbf{9}\end{array}$ & $\begin{array}{c}\text { Single/Batch } \\
\text { Picking 12 }\end{array}$ & $\begin{array}{c}\text { Batch Picking } \\
\mathbf{3}\end{array}$ & $\begin{array}{c}\text { Batch Picking } \\
\mathbf{6}\end{array}$ & $\begin{array}{c}\text { Batch Picking } \\
\mathbf{9}\end{array}$ \\
\hline FRT & $29 \%$ & $25 \%$ & $22 \%$ & $21 \%$ & $15 \%$ & $18 \%$ & $19 \%$ \\
\hline BT & $5 \%$ & $17 \%$ & $28 \%$ & $32 \%$ & $14 \%$ & $23 \%$ & $31 \%$ \\
\hline PT & $66 \%$ & $58 \%$ & $50 \%$ & $47 \%$ & $71 \%$ & $59 \%$ & $50 \%$ \\
\hline
\end{tabular}

\section{CONCLUSION}

The paper presents a comprehensive approach to research on order picking system productivity. It proves that reliable and conclusive assessment of order picking processes is crucial and requires including a large number of system components. Main attention was paid to pickers blocking in picking area. Authors researched impact of different storage policies, 
picking strategies and number of pickers on congestion and picking efficiency in specific conditions.

Simulation revealed that picking efficiency is directly correlated with the number of pickers. It increases (disproportionately) with the increase in the number of pickers, but more pickers leads to congestion and cuts the picking efficiency. Volume-based storage policies are more efficient for order picking than the class-based. Volume-based policies cause shorter order picking times, shorter pickers blocking times and longer picking paths. The number of material units per SKU that are offered in order picking area is crucial. In proposed analysis volume-based policies gave better results because in analysed variants many load unites per SKU were offered and congestion in aisles was smaller then. The further step is to analyse what is the optimal number of material units per SKU offered in picking area (for different storage policies) to minimise congestion and replenishment time.

The congestion is less sensitive for storage policies using pick regularity parameter the policies using pick frequency and pick volume. This is due to fact that SKUs' regularity has lower impact on blocking situations than their popularity. Additionally, batch picking leads to longer pickers blocking time than single picking.

The SimPick application can be used for analysing various "picker to part" and S-shape order picking systems and to simulate existing or planned order picking processes. It can be applied to solve academic and industrial issues as well. The application will be extended for new functionalities to allow modelling of the wider spectrum of order picking systems.

\section{REFERENCES}

[1] Klodawski, M.; Jacyna, M. (2012). Selected aspects of research on order picking productivity in aspect of congestion problems, Proceedings of the International Conference on Industrial Logistics (ICIL 2012), 204-210

[2] Lewczuk, K. (2015). The concept of genetic programming in organizing internal transport processes, The Archives of Transport, Vol. 34, No. 2, 61-74

[3] Lerher, T.; Brovinsek, M.; Ficko, M.; Palcic, I. (2017). Parametric study of throughput performance in SBS/RS based on simulation, International Journal of Simulation Modelling, Vol. 16, No. 1, 96-101, doi:10.2507/IJSIMM16(1)8.372

[4] Jacyna-Golda, I.; Lewczuk, K. (2017). The method of estimating dependability of supply chain elements on the base of technical and organizational redundancy of process, Maintenance and Reliability, Vol. 19, No. 3, 382-392, doi:10.17531/ein.2017.3.9

[5] Drury, J. (1988). Towards more efficient order picking, IMM Monograph No. 1, The Institute of Materials Management, Cranfield

[6] Tompkins, J. A.; White, J. A.; Bozer, Y. A.; Tanchoco, J. M. A. (2010). Facilities Planning, $4^{\text {th }}$ edition, John Wiley and Sons Ltd, Hoboken

[7] Li, Z. P.; Zhang, J. L.; Zhang, H. J.; Hua, G. W. (2017). Optimal selection of movable shelves under cargo-to-person picking mode, International Journal of Simulation Modelling, Vol. 16, No. 1, 145-156, doi:10.2507/IJSIMM16(1)CO2

[8] Huber, C. (2011). Throughput Analysis of Manual Order Picking Systems with Congestion Consideration, Dissertation, KIT Scientific Publishing, Karlsruhe

[9] Ottjes, J. A.; Hoogenes, E. (1988). Order picking and traffic simulation in distribution centres, International Journal of Physical Distribution \& Materials Management, Vol. 18, No. 4, 14-21, doi: $10.1108 / \mathrm{eb014696}$

[10] Ruben, R. A.; Jacobs, F. R. (1999). Batch construction heuristics and storage assignment strategies for walk/ride and pick systems, Management Science, Vol. 45, No. 4, 575-596, doi: $10.1287 / \mathrm{mnsc} .45 .4 .575$

[11] Thayalan, P. (2008). Comparative study of item storage policies, vehicle routing strategies and warehouse layouts under congestion, Master Thesis, State University of New York at Buffalo

[12] Gue, K. R., Meller, R. D., Skufca, J. D. (2006). The effects of pick density on order picking areas with narrow aisles, IIE Transactions, Vol. 38, No. 10, 859-868, doi:10.1080/07408170600809341 
[13] Parikh, P. J., Meller, R. D. (2009). Estimating picker blocking in wide-aisle order picking systems, IIE Transactions, Vol. 41, No. 3, 232-246, doi:10.1080/07408170802108518

[14] Parikh, P. J., Meller, R. D. (2008). Selecting between batch and zone order picking strategies in a distribution center, Transportation Research Part E: Logistics and Transportation Review, Vol. 44, No. 5, 696-719, doi:10.1016/j.tre.2007.03.002

[15] Furmans, K.; Huber, C.; Wisser, J. (2009). Queueing models for manual order picking systems with blocking, Logistics Journal, Vol. 1, 16 pages, doi:10.2195/LJ_Ref_Furmans_2092_092009

[16] Roodbergen, K. J. (2001). Layout and routing methods for warehouses, Ph.D. Thesis, Erasmus University Rotterdam, Rotterdam

[17] Kłodawski, M.; Żak, J. (2013). Order picking area layout and its impact on the efficiency of order picking process, Journal of Traffic and Logistics Engineering, Vol. 1, No. 1, 41-45, doi:10.12720/jtle.1.1.41-45

[18] Le-Duc, T. (2005). Design and control of efficient order picking processes, Ph.D. Thesis, Erasmus University Rotterdam, Rotterdam

[19] Dukic, G.; Oluic, C. (2004). Order-picking routing polices: simple heuristics, advanced heuristics or optimal algorithm, Strojniski vestnik - Journal of Mechanical Engineering, Vol. 50, No. 11, 530-535

[20] Roodbergen, K. J.; de Koster, R. (2001). Routing order pickers in a warehouse with a middle aisle, European Journal of Operational Research, Vol. 133, No. 1, 32-43, doi:10.1016/S03772217(00)00177-6

[21] De Koster, R.; Le-Duc, T.; Roodbergen, K. J. (2007). Design and control of warehouse order picking: a literature review, European Journal of Operational Research, Vol. 182, No. 2, 481501, doi:10.1016/j.ejor.2006.07.009

[23] Heskett, J. L. (1963). Cube-per-order index - a key to warehouse stock location, Transport and Distribution Management, Vol. 3, April Issue, 27-31

[24] Malmborg, C. J. (1995). Optimization of cube-per-order index warehouse layouts with zoning constraints, International Journal of Production Research, Vol. 33, No. 2, 465-482, doi: $10.1080 / 00207549508930160$

[25] Malmborg, C. J.; Bhaskaran, K. (1990). A revised proof of optimality for the cube-per-order index rule for stored item location, Applied Mathematical Modelling, Vol. 14, No. 2, 87-95, doi:10.1016/0307-904X(90)90076-H

[22] Brynzér, H.; Johansson, M. I. (1996). Storage location assignment: using the product structure to reduce order picking times, International Journal of Production Economics, Vols. 46-47, 595603, doi:10.1016/0925-5273(94)00091-3

[26] Le-Duc, T.; De Koster, R. (2005). Layout optimization for class-based storage strategy warehouses, de Koster, R.; Delfmann, W. (Eds.), Supply Chain Management - European Perspectives, CBS Press, Copenhagen, 191-214 